\title{
Mixed oxide growth on combinatorial aluminium-gadolinium alloys - a thermodynamic and first-principles approach
}

\author{
Khurram Shahzad $^{1} \cdot$ Cezarina Cela Mardare $^{1,2} \cdot$ Andrei lonut Mardare $^{1}$ D $\cdot$ Achim Walter Hassel $^{1,2,3}$
}

Received: 1 May 2021 / Revised: 14 July 2021 / Accepted: 15 July 2021 / Published online: 26 July 2021

(c) The Author(s) 2021

\begin{abstract}
Metal surfaces covered with oxides have attracted considerable scientific attention in various applications. In particular, anodic films fabricated by cost-effective anodizing have been widely used in nano-structured engineering to provide various surface functionalities. However, understanding of alloy film stability, having individual elements with widely varying structures and morphologies, is very limited due to lack of thermodynamic information and effects of electrolyte chemistry. This requires many tedious efforts on a trial and error basis in selecting suitable electrolytes that can produce the protective film at high efficiency on alloys having mixed chemistries. It is, therefore, crucial to develop a combination of high throughput theoretical analysis and automated rapid localized electrochemical probing that provides a fast and simple solution for electrolyte choice and paves the way to the remarkable expansion of industrial applications of oxides. Herein, we demonstrate that combinatorial Al-Gd alloys covering 1.0 to 10.0 at.\% $\mathrm{Gd}$ can be oxidized into ultra-thin anodic films of controlled thickness through a selection of electrolyte based on thermodynamics (phosphate buffer with a pH of 8.20). We propose that growth of anodic films on alloys at high efficiency is possible if Gibbs free energy minimization criteria would be systematically contemplate.
\end{abstract}

Keywords Anodizing $\cdot$ Rare earths $\cdot$ Combinatorial $\cdot$ Scanning droplet cell microscopy

\section{Introduction}

The "1-to-1" approach involving one system, one calculation, and one experiment at a time is now regarded as the traditional, time consuming, and outdated method in materials research, when there is an ever-increasing need for strategies to develop advanced materials with novel functionalities [1, 2]. The intelligent strategies play a crucial role in technologies ranging from electronics, energy generation and storage, aerospace, medicine, and defence industry [3-5]. To

Andrei Ionut Mardare

andrei.mardare@jku.at

1 Institute of Chemical Technology of Inorganic Materials, Johannes Kepler University Linz, Altenberger Str. 69, 4040 Linz, Austria

2 Danube Private University, Steiner Landstrasse 124, 3500 Krems-Stein, Austria

3 Christian Doppler Laboratory for Combinatorial Oxide Chemistry (COMBOX) at the Institute for Chemical Technology of Inorganic Materials, Johannes Kepler University Linz, Altenberger Str. 69, 4040 Linz, Austria achieve these technologies, attention has been given recently to integrate high-throughput first-principles calculations and combinatorial methods to obtain robust, extrapolative tools for gaining insights into structure-property-composition relationships in order to reduce the experimental efforts, time, and cost in the materials discovery process [6-13].

$\mathrm{Ab}$ initio or first-principles computational methods are becoming important in new materials discovery [14]. Scheming fabrication strategies using high-throughput computational approaches provide numerous benefits over traditional experimental-based materials discovery methods. Estimating material's fundamental properties is often faster with computation tools, when compared to the experiment, and properties of thousands of materials can be calculated in a relatively short period of time. Additionally, it is often trivial in calculations to simulate the effects of chemical substitutions or lattice strain, but achieving these through experiments could take many months of painstaking laboratory work. Thus, computations are effective tools for designing new materials [15-17]. Directly linked to this, combinatorial approaches are defined by the development of a "library" that comprises a material parameter of 
interest (usually dependent on the gradient in composition) addressed by rapid, local, and automated measurements creating a large data set. These data sets are examined to find a trend between composition, structure, and property of interest. In other words, combinatorial methods are generally faster and less expensive than traditional "1-to-1" material fabrication approaches. Furthermore, since all experiments are performed on the same graded-library with the same measurement tools and identical specimen preparation and storage history, a comprehensive and reliable data set can be generated $[1,18,19]$.

The applications of these intelligent strategies are important, in particular, to rapidly explore the lesser-known and rarely explored rare-earth elements (REEs) and their alloys. The understanding and fabrication of REEs and their alloys through the electrochemical route are very limited due to the lack of both experimental and theoretical literature. As an example, very few efforts have been made to explore the properties of the central atom of lanthanoid series, the gadolinium $(\mathrm{Gd})$, and its oxide $\left(\mathrm{Gd}_{2} \mathrm{O}_{3}\right)$. Gadolinium orthoaluminate $\left(\mathrm{GdAlO}_{3}\right)$ mixed oxide possesses excellent magnetic and antiferromagnetic properties [20-22]. The pure oxide $\mathrm{Gd}_{2} \mathrm{O}_{3}$ is a wide bandgap material (5.37-6.37 eV) [23] and meets the low leakage current requirement in CMOS applications [24]. The superior optical properties of $\mathrm{Gd}_{2} \mathrm{O}_{3}$ thin films make them efficient for use in optical applications $[23,25,26]$. Hong et al. reported that $\mathrm{Gd}_{2} \mathrm{O}_{3}$ is an excellent dielectric material to passivate GaAs surface, with a dielectric constant of 10 for epitaxial cubic phase and a low leakage current density of $10^{-9}-10^{-10} \mathrm{~A} \mathrm{~cm}^{-2}$ at zero bias [27], while Zhou et al. have found out a value of 20 for $\mathrm{Gd}_{2} \mathrm{O}_{3}$ thin-film [28]. This indicates that changing the substrate and growth method affects the anisotropic polycrystalline film growth, which can enhance its dielectric constant. The dielectric constant of $\mathrm{Gd}_{2} \mathrm{O}_{3}$ can be further used to modify the dielectric behaviour of aluminium-based alloys. The dielectric constant is one of the factors responsible for capacitance enhancement, and portable electronic devices have increased the demand for small-size electrolytic capacitors with high capacitance, low equivalent series resistance, and low leakage current [29, 30]. Materials with high dielectric constants are also crucial in many areas of modern microelectronics for miniature supercapacitors, infrared detectors, radar absorbing coatings, and holographic devices. Thus, there is a growing interest in the synthesis and precise characterization of materials with high dielectric constants and low leakage currents.

The comprehensive understanding of oxide behaviour in a solution can be enhanced by combining theoretical predictions with localized measurements. The localized analysis is critical as the dielectric properties are generally dependent on the material geometries and crystalline orientations [31]. At microscale, properties may be very different than those at macroscale. It is therefore crucial to probe these properties at a scale where inhomogeneities may be specially resolved. The development of scanning droplet cell microscopy (SDCM), in particular, has allowed for spatially resolved electrochemical characterization of surfaces [32-34]. Coupling SDCM with electrochemical impedance spectroscopy (EIS) may even determine the grain-specific responses and has superior control of the working area [31-36].

In this study, we take advantage of computational and combinatorial strategies to explore the composition, structure, and properties relationship systematically in Al-Gd alloys. For this purpose, the predictions of possible stable phases in a given electrochemical system were obtained from conventional potential-pH (or E-pH) diagrams and DFT simulated compositional phase diagrams and E-pH diagrams. This permits a rapid identification of anodizing electrolytes over a wide $\mathrm{pH}$ range for fabrication of $\mathrm{Al}-\mathrm{Gd}$ alloys in an ultra-fast manner and calculations of material specific parameters.

\section{Experimental methods}

Laterally graded Al-Gd alloy library was obtained by thermal co-deposition of the $\mathrm{Al}$ and $\mathrm{Gd}$ from two separated sources on borosilicate float glass substrates (VWR International $\mathrm{GmbH}$, Germany) having dimensions of $2.6 \times 7.6 \mathrm{~cm}^{2}$. A thermal co-evaporator with a base pressure of $10^{-5} \mathrm{~Pa}$ was used for co-deposition of $\mathrm{Al}$ and $\mathrm{Gd}$. The compositional control along the library was obtained by individually adjusting the deposition rate of each source. Specific details of the hardware used for library deposition were previously reported [37]. A low Gd amount was desired along the library, thus deposition rates of 0.9 and $0.1 \mathrm{~nm} \mathrm{~s}^{-1}$ were used for $\mathrm{Al}$ and $\mathrm{Gd}$, respectively, to obtain a compositional spread of approximately 9 at.\% along the length of the substrate. A total film thickness of $350 \mathrm{~nm}$ was obtained at the middle of Al-Gd library. It is worth mentioning here that the compositional spread of a library is limited by the particularities of the cosine law governing the thickness uniformity of alloying element taken separately along the substrate. For Gd contents above 10 at.\%, a new compositional spread needs to be prepared. However, higher Gd contents would result in formation of various intermetallics, which is not desired here.

Immediately after Al-Gd library deposition, scanning energy-dispersive X-ray (SEDX) spectroscopy was used for compositional mapping of the $\mathrm{Al}-\mathrm{Gd}$ spread. Each alloy was measured at discreet surface locations and their quantitative analysis was performed using IDFix software (remX $\mathrm{GmbH}$, France). The Gd amount varied between 1.0 and 10.0 at.\% along the library, while the $\mathrm{Al}$ concentration varied complementarily between 99.0 and 90.0 at.\%. This defines 
a compositional resolution of the Al-Gd thin film library of 0.12 at. $\% \mathrm{~mm}^{-1}$. For an usual requirement of 1 at.\% precision for alloy identification, more than $7 \mathrm{~mm}$ are thus available on the surface of the library for characterizing a single $\mathrm{Al}-\mathrm{Gd}$ alloy. This resulting area is quite convenient for being addressed by other investigation techniques for Al-Gd alloy property mappings. X-ray diffraction (XRD) was used to map the crystallographic particularities of Al-Gd alloys as a function of their composition. The experiments were performed in $\theta-2 \theta$ (Bragg-Brentano) and $\omega-2 \theta$ with $\omega=3^{\circ}$ (grazing incidence) geometries with $\mathrm{CuK}_{\alpha}$ radiation. Additionally, the surface morphologies of individual Al-Gd alloys (defined by EDX mapping) were characterized by scanning electron microscope (SEM-Zeiss Gemini 1540 $\mathrm{XB})$ before and after anodization.

The electrochemical measurements on thermally codeposited Al-Gd films were carried out using the SDCM in contact mode [32] at ambient temperature and pressure. The SDCM is a three-electrode system containing two channels in V-geometry, serving as inlet and outlet for the electrolyte. A Pt wire positioned in the electrolyte supply compartment served as counter electrode while a $\mathrm{Hg} / \mathrm{Hg}_{2} \mathrm{Cl}_{2} \mu$-reference electrode was placed in the drain compartment for avoiding chloride contaminations [38]. The Al-Gd thin film library deposited on glass substrates served as working electrode. The addressed area $\left(0.049 \mathrm{~cm}^{2}\right)$ was determined by SEM examination of anodically grown films. A steady flow of electrolyte is provided by a peristaltic pump that works as both electrolyte supply and drain at a constant rate.

All measurements were carried out using self-developed Labview software that controls the scanning of the SDCM tip along the library (using an XY translation stage) and monitors the applied force during contact. In this way, a single droplet of electrolyte is moved along the surface. At each unique $\mathrm{XY}$ position which also corresponds to unique alloy composition, open-circuit potential (OCP) was measured for $180 \mathrm{~s}$ in $0.2 \mathrm{M}$ phosphate buffer having a $\mathrm{pH}$ value of 8.20 (Fig. 1). The buffer solution was obtained by mixing anhydrous potassium phosphate monobasic and sodium phosphate dibasic heptahydrate. Following OCP recording, Al-Gd alloys were locally anodized potentiodynamically to $10 \mathrm{~V}$. Film resistance and dielectric properties of grown films were determined by simultaneously coupling EIS with cyclic voltammograms (CV) using a Compact Stat electrochemical interface system (IVIUM Technology, The Netherlands) with an $\mathrm{AC}$ amplitude of $50 \mathrm{mV}$ in a frequency range of $10^{5}$ to $10^{-1} \mathrm{~Hz}$. All impedance spectra in the present study were recorded at $0 \mathrm{~V}$ vs. SHE. The present study was conducted using the constant electrolyte flow from inlet to outlet compartments within the SDCM body. This ensured fresh electrolyte at the contact with the working electrode during combined CV-EIS measurements. The protocols followed in the electrochemical study is as follows: (1) positioning of

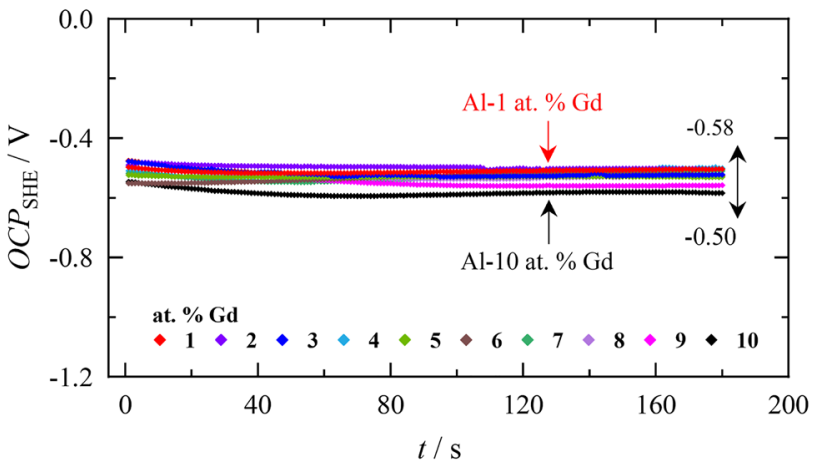

Fig. 1 Open circuit potential (OCP) of compositionally graded AlGd alloy library in phosphate buffer having $\mathrm{pH} 8.20$ for $180 \mathrm{~s}$

cell at a given location on the substrate and OCP recording, (2) anodic sweep $\left(100 \mathrm{mV} \mathrm{s}^{-1}\right)$ from OCP value measured before, (3) EIS measurement of grown film, (4) looping of $(1-3)$ to $10 \mathrm{~V}$ at $1 \mathrm{~V}$ incremental step. A more detailed description of the microelectrochemical flow measurement can be found elsewhere $[6,32,39]$. The thermodynamic data and electrochemical reactions used in the present study were taken from different sources [40-46]. Information regarding formation energies of species was taken from an open source web application [47]. The E-pH diagrams from firstprinciples DFT calculations were constructed from the highthroughput infrastructure developed by Jain et al. [46, 47], where experimentally determined free energies of aqueous ions and DFT energies for solid phases were used to construct multi-element compositional phase diagrams and E-pH diagrams. First-principles Car-Parinello molecular dynamics was used for simulations of aqueous states [48]. All E-pH diagrams were calculated at $298 \mathrm{~K}$ and atmospheric pressure for dissolved concentrations of species per litre of water.

\section{Results and discussion}

\section{Film structure and morphology}

The crystallographic properties of individual alloys were examined in both $\theta-2 \theta$ and $\omega-2 \theta$ modes along the $\mathrm{Al}-\mathrm{Gd}$ library. XRD analysis was performed at various $\mathrm{Al}: \mathrm{Gd}$ ratios and selected XRD patterns are presented in Fig. 2 as a function of Gd concentration. Aluminium possesses fcc symmetry, whereas Gd has a hexagonal structure. Additional phases other than $\mathrm{Al}$ were not found and the addition of Gd did not induce tri-aluminide intermetallic phase. Significant reduction in $\mathrm{Al}(111)$ peak intensity is observed when mapping from higher to lower Gd concentration. This could be due to variation in $\mathrm{Al}$ and $\mathrm{Gd}$ ratios as well as the gradual loss of crystallinity which indicates the influence of Gd concentration. 


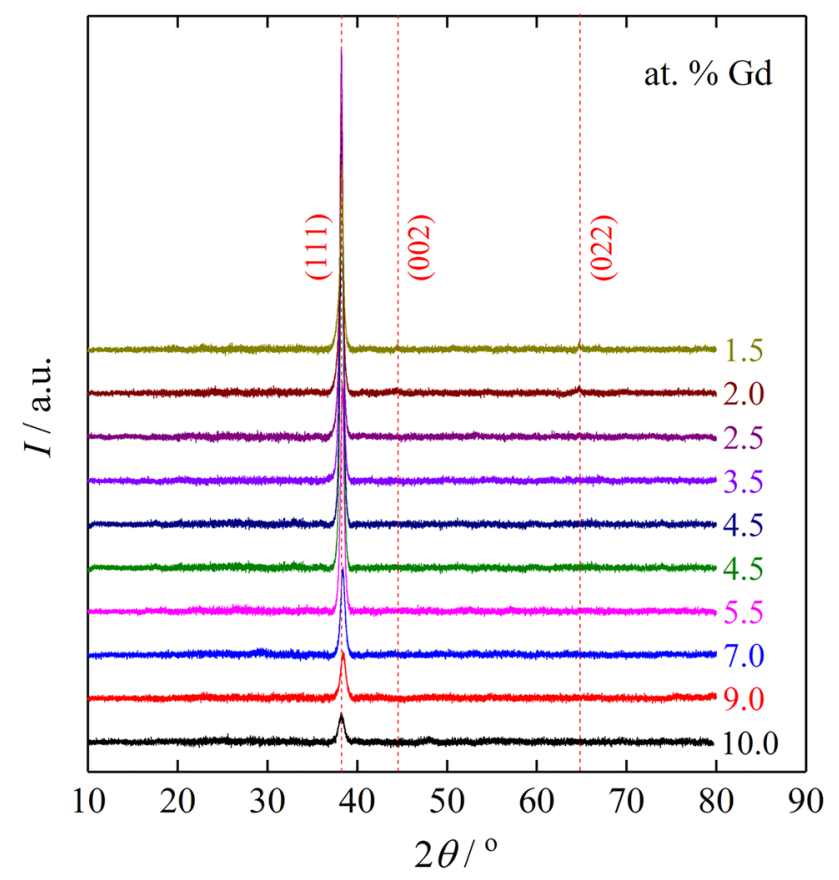

Fig. 2 XRD pattern of thermally evaporated Al-Gd combinatorial alloys ranging from 1.5 to 10.0 at.\% Gd

The binary Al-RE phase diagram and detailed analysis of Al-RE systems by Gschneidner et al. [49] indicate that $\mathrm{GdAl}_{3}$ tri-aluminide intermetallic phase is formed between 0 and 25 at.\% $\mathrm{Gd}$ addition to the $\mathrm{Al}$ matrix. The formation of the $\mathrm{REAl}_{3}$ phase is linked with the transformation of the structure from predominately hexagonal to cubic for the light lanthanoids having large radii ( $\mathrm{La}, \mathrm{Ce}, \mathrm{Nd}, \mathrm{Pr}, \mathrm{Sm}$, and $\mathrm{Gd}$ ). Contrary to binary Al-Gd phase diagram and Gschneidner et al. prediction, the absence of the $\mathrm{GdAl}_{3}$ phase may be attributed to the low sensitivity of the XRD analysis at nmdepth scale. Additionally, $\mathrm{Al}$ rich-phase predominates in the alloy matrix, and it is likely that the presence of $\mathrm{GdAl}_{3}$ is eclipsed by the Al-rich matrix.

The surface morphologies along the Al-Gd compositional spreads before and after electrochemical studies were examined by SEM. The SEM images prior to anodizing were taken in the vicinity of anodizing spot for each composition. Figure 3 shows the map of the observed morphologies from 1.5 to 10 at.\% $\mathrm{Gd}$, and the composition of each investigated region is given at the upper left corner. The microstructural analysis discloses a gradual change in surface morphology as the Gd content in the $\mathrm{Al}$ matrix increases (Fig. 3a) and can be divided into three distinct parts. The typical $\mathrm{Al}$ grains can be seen in the first line of SEM images, ranging from 1.5 to 2.5 at. $\% \mathrm{Gd}$. The suppression of large grains and gradual formation of mixed morphology are evident from 3.5 to 5.5 at.\% Gd (second line), where the imprint of surface grains and grain boundaries still can be seen. A noticeable change in the surface morphology and distinct features with thick upright needles can be observed from 7.0 to 10 at.\% Gd. Moreover, the change in surface features with Gd addition agrees well with XRD analysis, where the reduction in peak intensity and loss of crystallinity were attributed to variation of the $\mathrm{Al}: \mathrm{Gd}$ ratio.

Surface morphologies after anodizing reveal a significant change and show a network of bright lines on the original Al grains, as can be readily seen from the SEM image in Fig. 3b. Because of their strong adsorption on the metal surface, the possibility of phosphate precipitates cannot be overlooked. No signs of localized corrosion or pitting was found in SEM observation.

\section{Electrochemical studies}

Composition and structural complexity in binary Al-RE alloys render the electrochemical measurement unstable [50]. One alloy constituent may dissolve preferentially in a certain $\mathrm{pH}$ range leaving the other constituent unaffected. Structure and morphological complexity due to lattice mismatch and a large difference in atomic and ionic radii further complicate the understanding of dissolution susceptibility in a specific $\mathrm{pH}$ range. Consequently, predicting thermodynamically auspicious conditions for anodizing multi-component systems is a meticulous task due to a large number of competing reaction pathways and end products. Additionally, the classical E-pH diagrams do not address the alloy- $\mathrm{H}_{2} \mathrm{O}$ systems, thereby producing a gap in the theoretical understanding of Al-RE alloys [40, 41, 51, 52]. Hence, a theoretical framework is also developed in the present study, which can readily foresee the thermodynamic feasibility of reactions, stable phases in a complex Al-Gd-P-O-H system. For instance, conventional E-pH diagrams do not reveal the presence of $\mathrm{AlPO}_{4}$, and $\mathrm{GdPO}_{4}$ phases in $\mathrm{Al}-\mathrm{H}_{2} \mathrm{O}$ and $\mathrm{Gd}-\mathrm{H}_{2} \mathrm{O}$ aqueous systems. Consequently, calculations of material specific parameters and analysis of film properties would remain incomplete without considering missing phases in conventional E-pH diagrams.

In order to find a compromise $\mathrm{pH}$ range for $\mathrm{Al}-\mathrm{Gd}$ alloys in phosphate buffer, the conventional E-pH diagrams $\mathrm{Al}-\mathrm{H}_{2} \mathrm{O}, \mathrm{Gd}-\mathrm{H}_{2} \mathrm{O}, \mathrm{P}-\mathrm{H}_{2} \mathrm{O}$ systems were simulated from an experimental database [40-44] and superimposed on each other. Figure 4a shows the superimposition of $\mathrm{Al}-\mathrm{H}_{2} \mathrm{O}$ and $\mathrm{Gd}-\mathrm{H}_{2} \mathrm{O}$ systems, while Fig. $4 \mathrm{~b}$ reveals the superimposition of $\mathrm{Gd}-\mathrm{H}_{2} \mathrm{O}$ and $\mathrm{P}-\mathrm{H}_{2} \mathrm{O}$ systems. A different stability domain for $\mathrm{Gd}(\mathrm{OH})_{3}$ and $\mathrm{Gd}_{2} \mathrm{O}_{3}$ arises because of the difference in free energies for hydroxide and oxide formations (see Table 1). In other words, considering the metal hydroxide alone is not sufficient to predict the $\mathrm{pH}$ range even for a single metal. Figure $4 \mathrm{a}$ discloses that the domain of $\mathrm{Al}_{2} \mathrm{O}_{3}$ stability terminates at around $\mathrm{pH} 9.0$ and shifts towards lower $\mathrm{pH}$ range as the dissolved $\mathrm{Al}$ concentration 
Fig. 3 Surface morphologies along Al-Gd alloy library a before and $\mathbf{b}$ after anodizing at selected atomic concentrations of Gd. The Gd concentration in the alloy is given at the upper left corner of each figure. The SEM images were taken after room temperature anodizing at a sweep rate of $100 \mathrm{mV} \mathrm{s}^{-1}$ to $10 \mathrm{~V}$ in $0.2 \mathrm{M}$ phosphate buffer having a $\mathrm{pH}$ value of 8.20
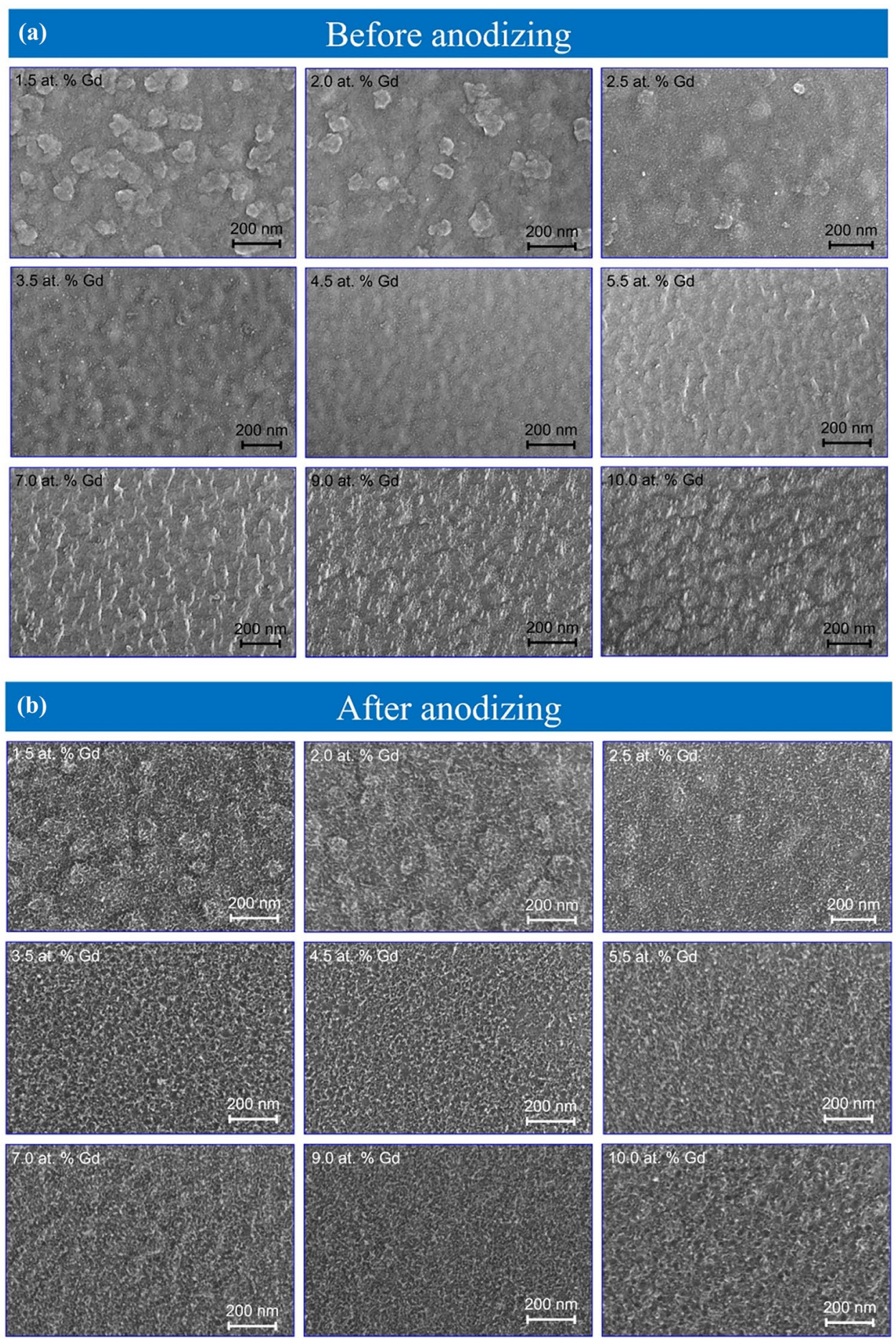

in the solution reduces. Additionally, passive domains in the $\mathrm{Gd}-\mathrm{H}_{2} \mathrm{O}$ system begin at around $\mathrm{pH} 9.0$ and moves towards higher $\mathrm{pH}$ values when the concentration of dissolved Gd is decreased in the solution. Simultaneous oxidation of $\mathrm{Al}$ and $\mathrm{Gd}$ alloys at high efficiency or at a nearly equal amount of dissolved concentrations of both metals is not thermodynamically feasible in the aqueous electrolyte at any $\mathrm{pH}$ value. Consequently, oxide-forming species such as phosphate and borate are needed to shift the passive domains of both metals. However, it was further found out that superimposing conventional $\mathrm{pH}$ diagrams of metal- $\mathrm{H}_{2} \mathrm{O}$ systems with oxide-forming species does not modify the E-pH diagrams. One reason for this is that superimposed diagrams do not incorporate the reactions between metals and oxideforming species. Thus, it is not possible to progress in the understanding of an alloy anodizing in a complex aqueous 
Table 1 Literature survey of chemical and electrochemical reactions and standard Gibbs free energy of formation for selected systems [40-45]

\begin{tabular}{|c|c|c|c|}
\hline Chemical and electrochemical reactions & $\Delta G\left(\mathrm{~kJ} \mathrm{~mol}^{-1}\right)$ & Species & $\frac{\boldsymbol{o}}{\Delta G\left(\mathrm{~kJ} \mathrm{~mol}^{-1}\right)}$ \\
\hline \multicolumn{4}{|l|}{$\mathrm{H}_{2} \mathrm{O}$} \\
\hline \multirow[t]{3}{*}{$2 \mathrm{H}_{2} \mathrm{O}_{(\mathrm{l})} \rightarrow 4 \mathrm{H}^{+}+4 \mathrm{e}^{-}+\mathrm{O}_{2}(\mathrm{~g})$} & 474.27 & $\mathrm{H}_{2} \mathrm{O}$ & -237.370 \\
\hline & & $\mathrm{H}^{+}$ & 0 \\
\hline & & $\mathrm{e}^{-}$ & 0 \\
\hline \multicolumn{4}{|l|}{ Gd- $\mathrm{H}_{2} \mathrm{O}$ system } \\
\hline $\mathrm{Gd}^{3+}+3 \mathrm{e}^{-} \rightarrow \mathrm{Gd}(\mathrm{s})$ & 659.71 & $\mathrm{Gd}^{3+}$ & -659.710 \\
\hline $\mathrm{Gd}^{3+}+3 \mathrm{H}_{2} \mathrm{O} \rightarrow 3 \mathrm{H}^{+}+\mathrm{Gd}(\mathrm{OH})_{3}(\mathrm{~s})$ & 89.01 & $\mathrm{Gd}(\mathrm{OH})_{3}(\mathrm{~s})$ & -1282.81 \\
\hline $\mathrm{Gd}^{3+}+2 \mathrm{H}_{2} \mathrm{O} \rightarrow 4 \mathrm{H}^{+}+\mathrm{Gd}(\mathrm{OH})_{4}^{-}$ & 196.28 & $\mathrm{Gd}(\mathrm{OH})_{4}^{-}$ & -938.170 \\
\hline $2 \mathrm{Gd}^{3+}+3 \mathrm{H}_{2} \mathrm{O} \rightarrow \mathrm{Gd}_{2} \mathrm{O}_{3}+6 \mathrm{H}^{+}$ & 306.97 & $\mathrm{Gd}_{2} \mathrm{O}_{3}$ & -1724.56 \\
\hline \multicolumn{4}{|l|}{$\mathrm{Gd}-\mathrm{H}_{2} \mathrm{O}-\mathrm{PO}_{4}{ }^{3-}$ system } \\
\hline $\mathrm{Gd}^{3+}+2 \mathrm{PO}_{4}{ }^{3-} \rightarrow \mathrm{Gd}\left(\mathrm{PO}_{4}\right)_{2}{ }^{3-}$ & -118.11 & $\mathrm{Gd}\left(\mathrm{PO}_{4}\right)_{2}^{3-}$ & -2827.22 \\
\hline $2 \mathrm{H}^{+}+\mathrm{Gd}^{3+}+\mathrm{PO}_{4}{ }^{3-} \rightarrow \mathrm{GdH}_{2} \mathrm{PO}_{4}{ }^{2+}$ & -127.63 & $\mathrm{GdH}_{2} \mathrm{PO}_{4}{ }^{2+}$ & -1812.04 \\
\hline $\mathrm{Gd}^{3+}+\mathrm{PO}_{4}^{3-} \rightarrow \mathrm{GdPO}_{4}(\mathrm{~s})$ & -146.18 & $\mathrm{GdPO}_{4}(\mathrm{~s})$ & -1830.59 \\
\hline \multicolumn{4}{|l|}{$\mathrm{PO}_{4}{ }^{3-}-\mathrm{H}_{2} \mathrm{O}$ system } \\
\hline $\mathrm{P}(\mathrm{cr})+4 \mathrm{H}_{2} \mathrm{O} \rightarrow 8 \mathrm{H}^{+}+5 \mathrm{e}^{-}+\mathrm{PO}_{4}{ }^{3-}$ & -75.26 & $\mathrm{PO}_{4}^{3-}$ & -1024.74 \\
\hline $\mathrm{H}^{+}+\mathrm{PO}_{4}{ }^{3-} \rightarrow \mathrm{HPO}_{4}{ }^{2-}$ & -70.44 & $\mathrm{HPO}_{4}^{2-}$ & -509.020 \\
\hline \multicolumn{4}{|l|}{$\mathrm{Al}-\mathrm{H}_{2} \mathrm{O}$ system } \\
\hline $\mathrm{Al}^{3+}+3 \mathrm{e}^{-} \rightarrow \mathrm{Al}(\mathrm{s})$ & 481.0 & $\mathrm{Al}^{3+}$ & 481.0 \\
\hline $\mathrm{Al}^{3+}+3 \mathrm{H}_{2} \mathrm{O} \rightarrow 3 \mathrm{H}^{+}+\mathrm{Al}(\mathrm{OH})_{3}(\mathrm{~s})$ & 59.23 & $\mathrm{Al}(\mathrm{OH})_{3}(\mathrm{~s})$ & -1137.6 \\
\hline $\mathrm{Al}^{3+}+4 \mathrm{H}_{2} \mathrm{O} \rightarrow 4 \mathrm{H}^{+}+\mathrm{Al}(\mathrm{OH})_{4}^{-}$ & 129.52 & $\mathrm{Al}(\mathrm{OH})_{4}{ }^{-}$ & -310.92 \\
\hline $2 \mathrm{Al}^{3+}+3 \mathrm{H}_{2} \mathrm{O} \rightarrow \mathrm{Al}_{2} \mathrm{O}_{3}+6 \mathrm{H}^{+}$ & 91.81 & $\mathrm{Al}_{2} \mathrm{O}_{3}$ & -1582.3 \\
\hline \multicolumn{4}{|l|}{$\mathrm{Al}-\mathrm{H}_{2} \mathrm{O}-\mathrm{PO}_{4}{ }^{3-}$ system } \\
\hline $\mathrm{Al}^{3+}+\mathrm{PO}_{4}^{3-} \rightarrow \mathrm{AlPO}_{4}(\mathrm{~s})$ & -119.76 & $\mathrm{AlPO}_{4}(\mathrm{~s})$ & -1625.50 \\
\hline
\end{tabular}

medium by just superimposing a series of conventional Pourbaix diagrams, and this may often lead to false conclusions in predicting aqueous corrosion. Moreover, extracting thermodynamic information from published literature is a very time-consuming effort. Many alloys exhibit intriguing physical and chemical properties resulting from the complex interactions between the constituent's elements. Several known or unknown non-equilibrium compositions and structures can form in a material during its lifetime and at present, it is challenging to accurately simulate all of the relevant phases in a given system. In order to overcome this limitation, there is a need for an advanced approach to predict the realistic complex systems in a high-throughput manner. Therefore, to maximize the prediction of possible phases in the Al-Gd-P-H-O complex system, the grand canonical linear programming (GCLP) method [7, 9] and
Fig. 4 a Superimposed E-pH diagram of $\mathrm{Al}-\mathrm{H}_{2} \mathrm{O}$ and $\mathrm{Gd}-$ $\mathrm{H}_{2} \mathrm{O}$ systems. The diagrams are constructed at different molar concentrations of dissolved $\mathrm{Al}$ and $\mathrm{Gd}$ with exponents of $0,-3,-6$, and -8 in water at $298 \mathrm{~K}$; b superimposed E-pH diagram of $\mathrm{Gd}-\mathrm{H}_{2} \mathrm{O}$ and $\mathrm{P}-\mathrm{H}_{2} \mathrm{O}$ systems for $\mathrm{Gd}_{2} \mathrm{O}_{3} / \mathrm{Gd}(\mathrm{OH})_{3}$ formation at molar concentration per litre of water with exponent of -6
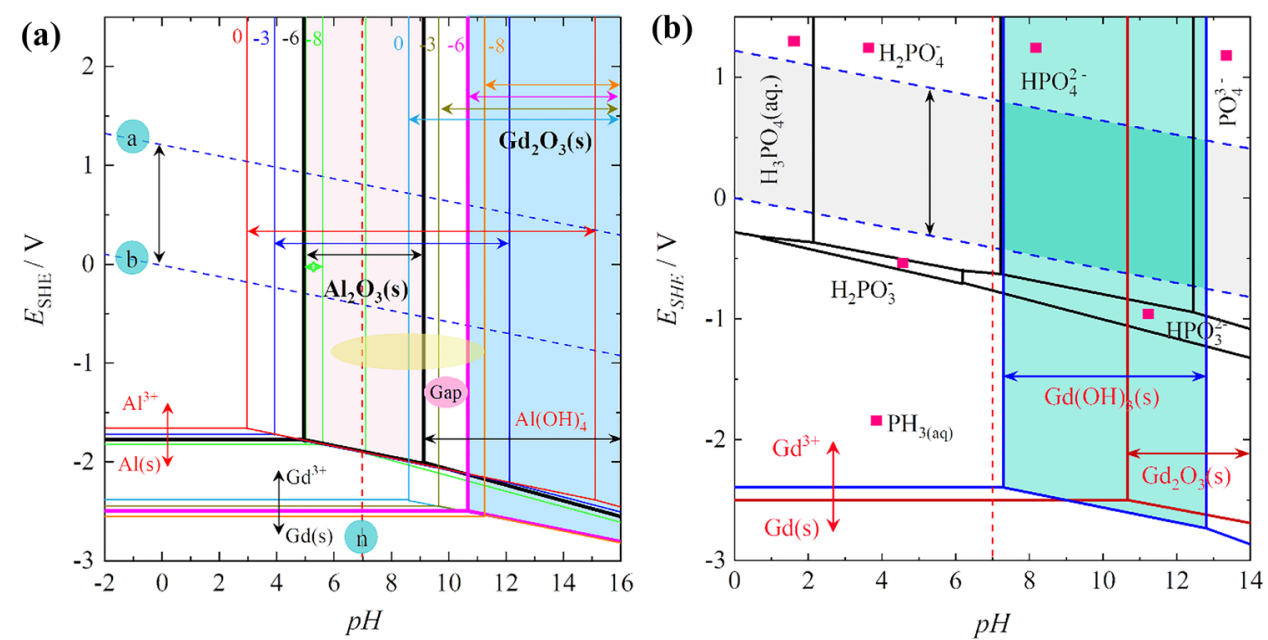
open-source web application [45-47] were also utilized for analysing the complex ground state thermodynamics. GCLP strategy works by mapping a free energy minimization problem as a linear algebra problem and this allows the computation of very large number of phases in a very highdimension phase space. The exemplary DFT simulated compositional phase diagrams for the identification of stable or metastable phases in $\mathrm{Al}-\mathrm{Gd}-\mathrm{P}-\mathrm{O}_{2}-\mathrm{H}_{2}$ system are provided in the supplementary Figures S1, S2 and S3. An example of implementation of above-mentioned approach to construct E-pH diagrams can be seen in Fig. 5, where stable phases found in compositional phase diagrams of $\mathrm{Al}-\mathrm{Gd}-\mathrm{P}-\mathrm{O}_{2}-\mathrm{H}_{2}$ system can be considered for E-pH diagrams of Al-P- $\mathrm{H}_{2} \mathrm{O}$ (Fig. 5a), Gd-P- $\mathrm{H}_{2} \mathrm{O}$ (Fig. 5b), Al-Gd-P- $\mathrm{H}_{2} \mathrm{O}$ (Fig. 5c) aqueous systems. Figure $5 \mathrm{~d}$ reveals the summary of enthalpy change estimated from DFT calculations for $\mathrm{Gd}_{2} \mathrm{O}_{3}-\mathrm{H}_{2} \mathrm{O}$, $\mathrm{Al}_{2} \mathrm{O}_{3}-\mathrm{H}_{2} \mathrm{O}, \mathrm{Al}_{2} \mathrm{O}_{3}-\mathrm{Gd}_{2} \mathrm{O}_{3}, \mathrm{Gd}_{2} \mathrm{O}_{3}-\mathrm{P}_{2} \mathrm{O}_{5}$, and $\mathrm{Al}_{2} \mathrm{O}_{3}-\mathrm{P}_{2} \mathrm{O}_{5}$ binary systems. It is obvious that phosphate incorporation remarkably modifies the E-pH diagrams of both constituents of the alloy and provides the protection of $\mathrm{Al}^{3+}$ and $\mathrm{Gd}^{3+}$ species around $\mathrm{pH}$ 6.0-9.0 (Fig. 5c) above $0 \mathrm{~V}$.
Consequently, phosphate-containing electrolyte was chosen between $\mathrm{pH} 6.0$ and 9.0. The oxide-forming species such as phosphate cannot be selected by just considering the free energies of species $\left(\mathrm{AlPO}_{4}\right.$ and $\left.\mathrm{GdPO}_{4}\right)$. There must be some thermodynamic $\mathrm{pH}$ range at which a specific electrolyte can be used. It is worth-mentioning here that the main objective of superimposed E-pH diagram computations was to identify the electrolyte and $\mathrm{pH}$ ranges. A similar framework can be designed for other electrolyte selection such as phosphatecitrate buffer, ammonium pentaborate tetrahydrate.

Following theoretical consideration and electrolyte selection, schematic and expected mixed oxide growth for the present study is shown in Fig. 6, which discloses the use of SDCM along Al-Gd library (a), oxidation of $\mathrm{Al}$ and $\mathrm{Gd}$ atoms upon application of formation voltage, $V$ and interaction of cations with the phosphate buffer $(b, c)$. The relative sizes of atomic and ionic radii of $\mathrm{Al}$ and $\mathrm{Gd}$ are noticeable before and after the application of $V$ as the migration rate of cations through the film depends on their sizes and bond energies. The oxidation of alloying elements in Al-binary alloys depends on Gibbs free energy per equivalent for the
Fig. 5 Simulated E-pH diagrams using first-principles DFT methods: a P-Al- $\mathrm{H}_{2} \mathrm{O}$ system at $a_{\mathrm{Al}^{3+}}=10^{-6} \mathrm{M}$, $a_{\mathrm{PO}_{4}^{3-}}=10^{-1} \mathrm{M} ; \mathbf{b} \mathrm{P}-\mathrm{Gd}-\mathrm{H}_{2} \mathrm{O}$ system at $a_{\mathrm{Gd}^{3+}}=10^{-6} \mathrm{M}$, $a_{\mathrm{PO}_{4}^{3-}}=10^{-1} \mathrm{M} ; \mathbf{c} \mathrm{P}-$ $\mathrm{Al}-\mathrm{Gd}-\mathrm{H}_{2} \mathrm{O}$ system at $a_{\mathrm{Al}^{3+}}=a_{\mathrm{Gd}^{3+}}=10^{-6} \mathrm{M}$, $a_{\mathrm{PO}_{4}^{3-}}=10^{-1} \mathrm{M}$. d Enthalpy change of oxide formation for $\mathrm{Gd}_{2} \mathrm{O}_{3}-\mathrm{H}_{2} \mathrm{O}, \mathrm{Gd}_{2} \mathrm{O}_{3}-\mathrm{P}_{2} \mathrm{O}_{5}$, $\mathrm{Gd}_{2} \mathrm{O}_{3}-\mathrm{Al}_{2} \mathrm{O}_{3}, \mathrm{H}_{2} \mathrm{O}-\mathrm{Al}_{2} \mathrm{O}_{3}$, and $\mathrm{P}_{2} \mathrm{O}_{5}-\mathrm{Al}_{2} \mathrm{O}_{3}$ binary oxide phase diagrams using first-principles DFT methods
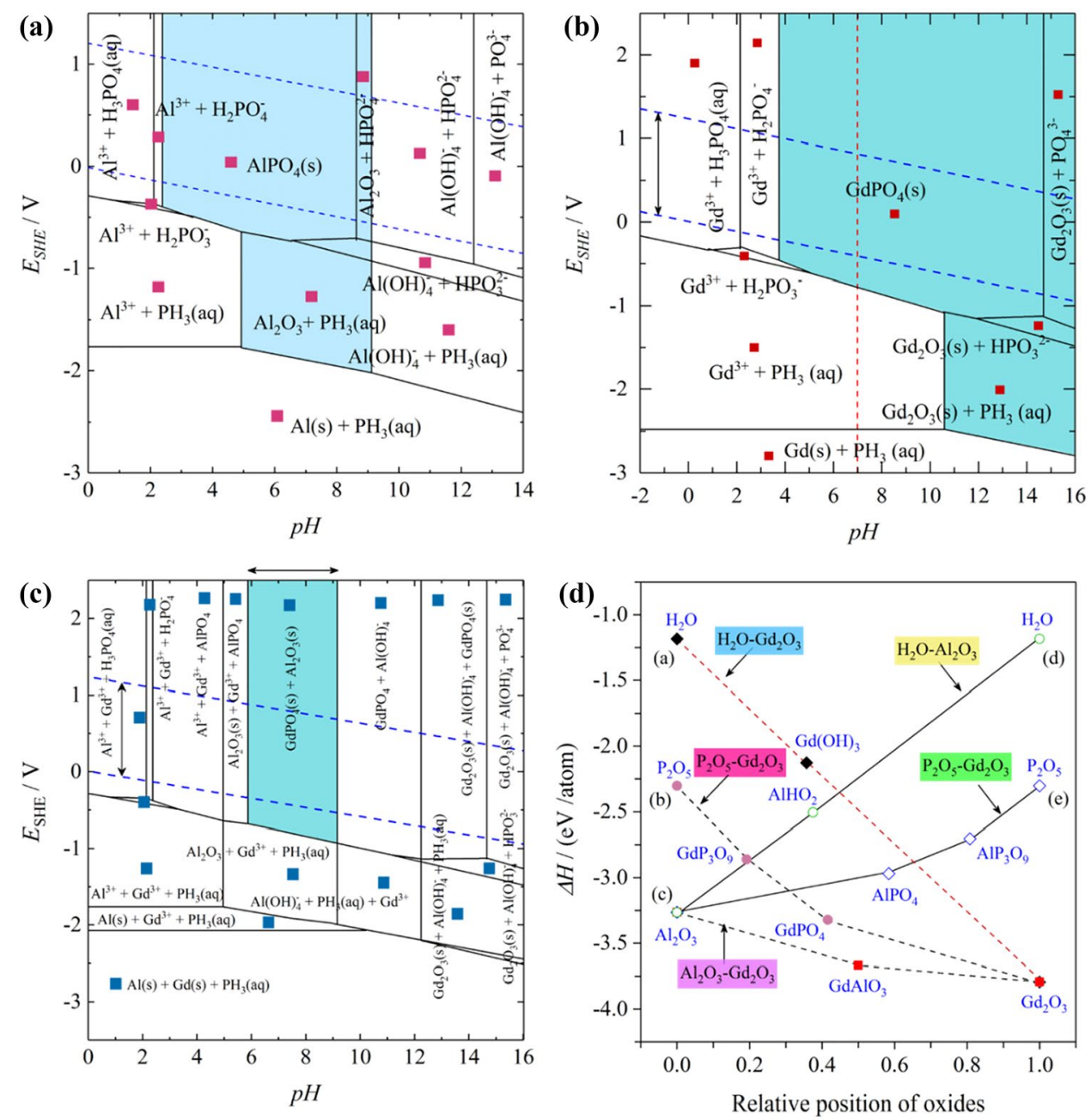


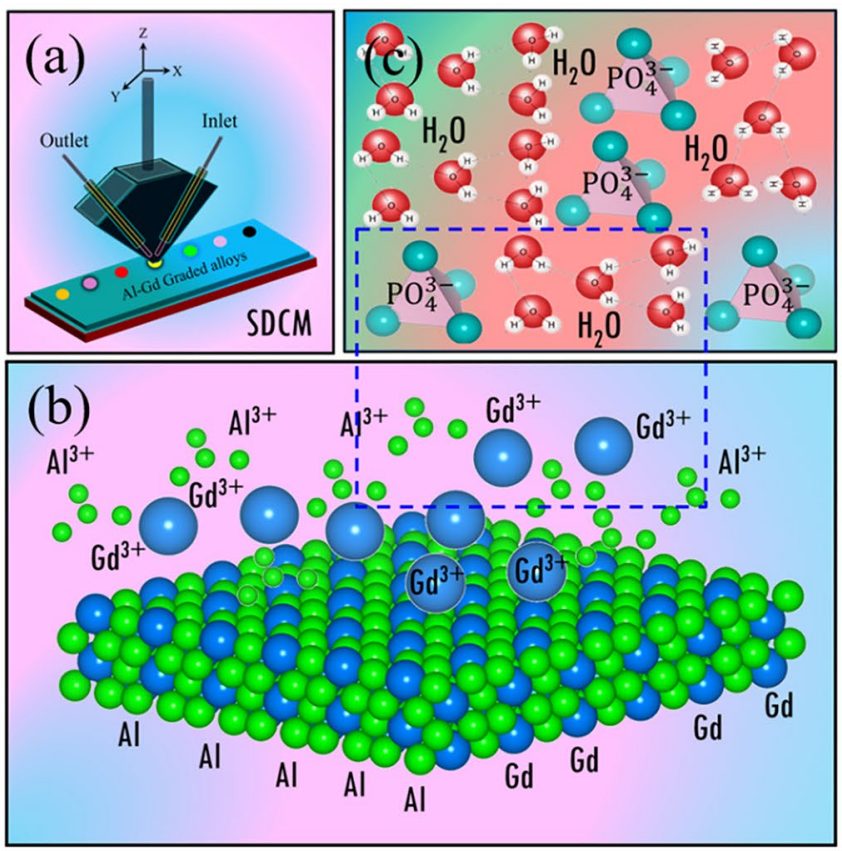

Fig. 6 Schematic of mixed oxide formation: a use of SDCM on evaporated film surface; $\mathbf{b}, \mathbf{c}$ interaction of mixed-structure with phosphate-containing aqueous electrolyte; $\mathbf{d}$ formation of mixed oxide and
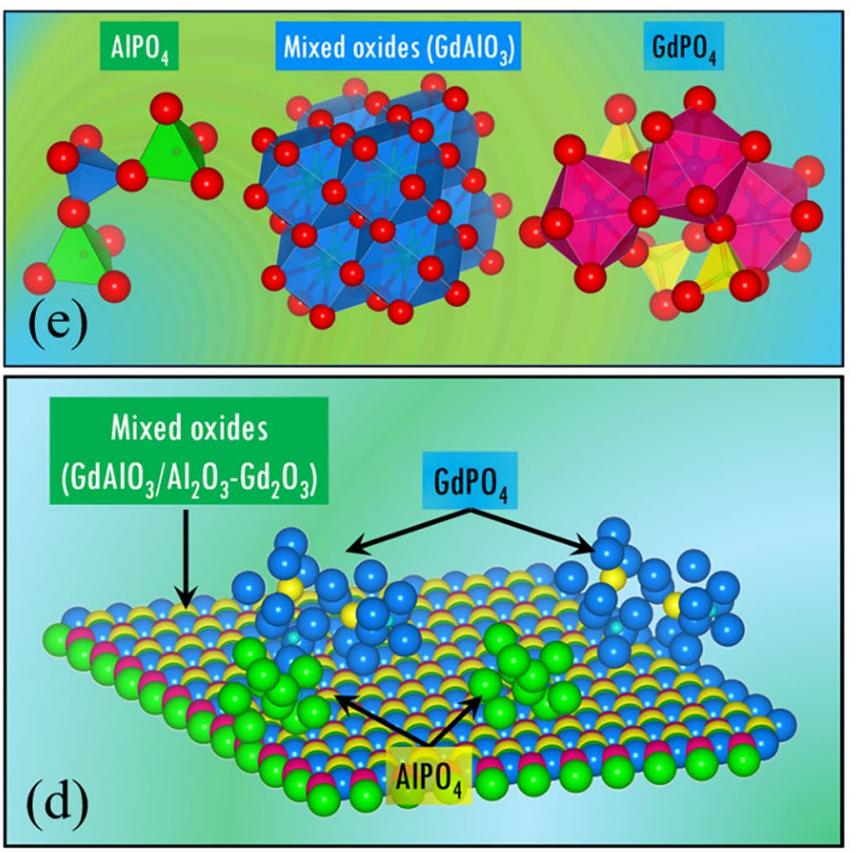

phosphate adsorption on film surface; e molecular structure of mixed oxide $\left(\mathrm{GdAlO}_{3}\right)$ and metal phosphates $\left(\mathrm{AlPO}_{4}\right.$ and $\left.\mathrm{GdPO}_{4}\right)$

of selected CVs is presented in Fig. 7 which corresponds to 110 potentiodynamic scans and EIS spectra. For each composition, a visible current density plateau can be readily observed which defines the charge consumed during the incremental growth process. This is due to the direct relationship between the charge transferred to the working electrode and the oxide volume grown following Faraday's law. This leads to the average oxide formation factor, $k_{\text {ave }}$ which can be defined as

$k_{\text {ave }}=\frac{\Delta d}{\Delta V}=\eta \frac{q K_{o x}}{V}$

where $K_{\mathrm{ox}}$ is a material constant, $d$ is the oxide thickness, $V$ is anodizing potential, $q$ is the charge consumed, and $\eta$ is the efficiency of the film formation current. $K_{\mathrm{ox}}$ can be defined in terms of oxide specific constants (mixed oxide molar mass, $M_{\mathrm{ox}}$, oxide density, $\rho_{\mathrm{ox}}$, and oxidation number, $z$, and Faraday's constant $F$ ) by the following equation:

$K_{\mathrm{ox}}=\frac{M_{\mathrm{ox}}}{z F \rho_{\mathrm{ox}}}$

The molecular masses and densities of mixed anodic films locally grown on the Al-Gd alloys library were estimated using the mixed-matter theory by means of linear distributions between the $\mathrm{Al}_{2} \mathrm{O}_{3}$ and $\mathrm{Gd}_{2} \mathrm{O}_{3}$. Owing to negligible dissolution of $\mathrm{Al}$ and $\mathrm{RE}$ in phosphate-containing electrolytes [58-65], a typical passive film current density plateau 
Fig. $7 \mathrm{CVs}$ at different atomic concentrations of $\mathrm{Gd}$ along the Al-Gd library. Each single alloy composition was electrochemically scanned in phosphate buffer ( $\mathrm{pH}$ 8.20) from $0 \mathrm{~V}$ to a maximum of $10 \mathrm{~V}$ and then scanned back to $0 \mathrm{~V}$. The $V$ was stepwise increased with $1 \mathrm{~V}$ increment

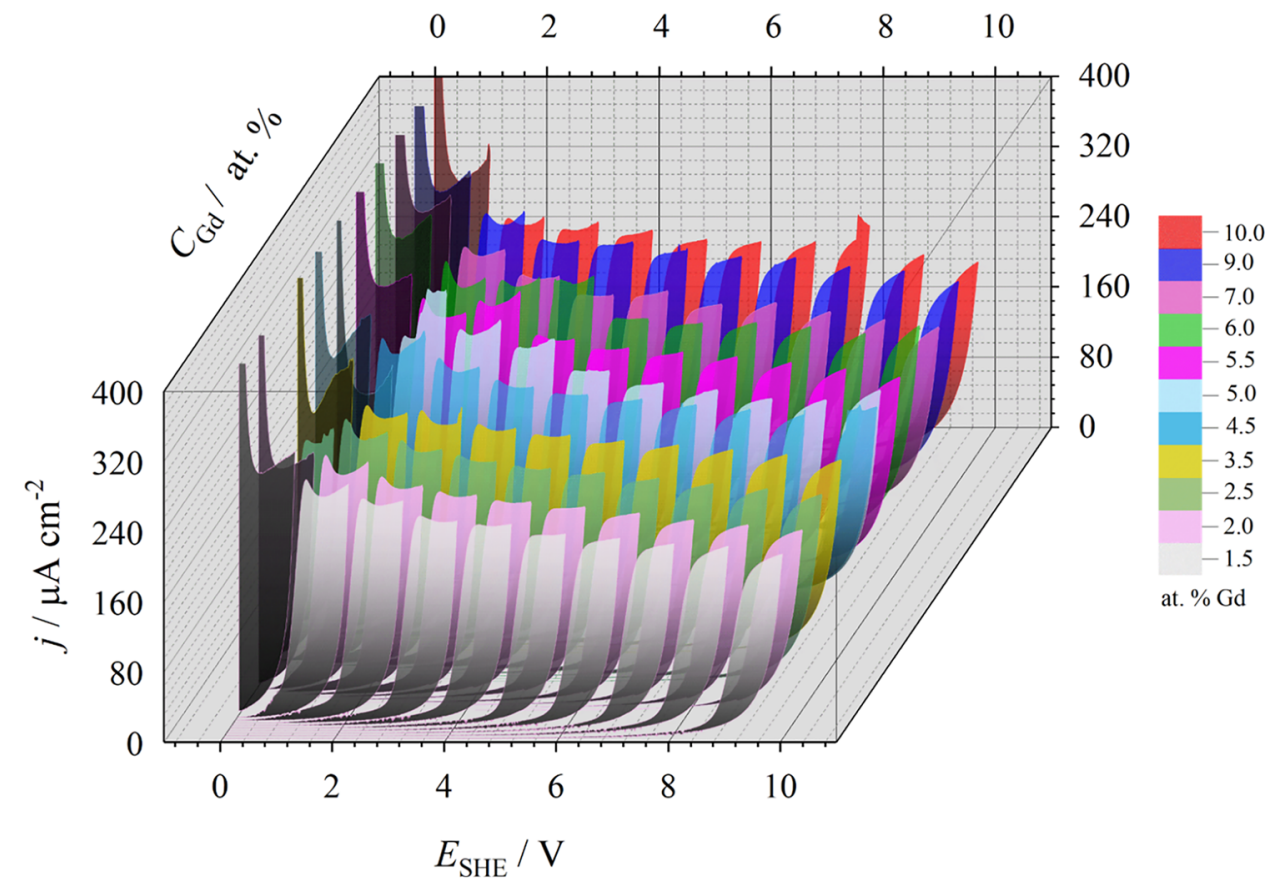

and negligible leakage current density response on reversal of potential sweep scans, the efficiency of film formation current $\eta$ can be assumed here as $100 \%$. Because of the large sizes of $\mathrm{GdPO}_{4}$ and $\mathrm{AlPO}_{4}$, it is expected that phosphate incorporation within the film would be extremely small. The extremely low dissolution of RE in phosphate-containing electrolyte was verified by coupling CV-EIS measurements and ICP-OES analysis in Al-Ho system ( 10-20 ppb) [64]. The current overshoots present at low potentials may be attributed to the delayed oxide growth due to the space charge layer formation or the sudden reaction of the metal surface to the electrolyte. Therefore, the CV and EIS data are excluded at $1 \mathrm{~V}$ in $k_{\text {ave }}$ calculation.

\section{Electrochemical impedance spectroscopy}

Bode and Nyquist plots for two extreme compositions are shown in Fig. 8. The impedance changes linearly as a function of frequency for all compositions, and gradually rises with $V$ implying a linear growth of the anodic film. The direction of arrows shows the increase in anodizing potential. As the film grows, an expected shift of phase angle towards $-90^{\circ}$ typical of dielectric oxide film is obtained. The value of phase shift, $\alpha$ obtained from impedance fitting was above 0.92 in all compositions.

Figures 8a, c show that regardless of film composition, Bode plots on a log scale show similar absolute impedance. The corresponding Nyquist plots on a linear scale in Fig. $8 \mathrm{~b}, \mathrm{~d}$ disclose the magnitude reduction in the imaginary component $\left(-Z_{i m g}\right)$ of impedance without affecting the real component $\left(Z_{r}\right)$. This indiactes that Gd addition affects the capacitance or dielectric properties and has no appreciable effect on the resistance of passive films. As the capacitance varies inversely with the impedance, it is envisaged that films comprising $\mathrm{Al}$ and $\mathrm{Gd}$ mixed oxides can be obtained by incorporating $\mathrm{Gd}$ with enhanced capacitance into $\mathrm{Al}$ matrix while retaining the film resistance, $R_{f}$ of pure alumina. Moreover, the phase shift behaviourr reveals that as oxide grows thicker, incremental $V$ not only induces a capacitive response, as evidenced by the magnitude of phase shift, but also widens the constant phase element (CPE).

The influence of $\mathrm{Gd}$ on dielctric constant can be obtained by a careful determination of capacitance through EIS fitting. Different approaches are used in the literature to calculate the true value of capacitance from CPE without considering the origin of the CPE [66-68]. It is difficult to implement a suitable CPE-C conversion model, thereby, the determination of capacitance from CPE data is often inadequate, leading to the erroneous prediction of physical properties [69-71]. For this reason, special consideration has been taken to understand the CPE behaviour for passive film growth.

The impedance of $R_{\mathrm{el}}\left(Q R_{f}\right)$ circuit exhibiting CPE behaviour having parameters $Q$ and $\alpha$ can be expressed as

$Z=R_{e l}+\frac{R_{f}}{1+Q(j \omega)^{\alpha} R_{f}}$

where $R_{\mathrm{el}}$ and $R_{\mathrm{f}}$ are the electrolyte and film resistances, respectively. Hirschorn et al. demonstrated the significance of employing the correct formula for a given distribution of time constants as well as impact on film properties [69]. 
Hsu and Mansfeld [67], on the other hand, considered the frequency, $\omega_{\max }$ on the top of the depressed semi-circle where the real part $\left(Z_{r}\right)$ lies midway between low and highfrequency $x$-axis intercepts on the Nyquist plot. As a result, multiple approaches are compared in order to accurately predict the capacitance, $C$ and $k_{\text {ave }}$ from CPE having parameters $Q$ and $\alpha$. The results for the $k_{\text {ave }}$-values were also compared with the $k_{\text {ave }}$ values obtained from Faraday's law (Table 2). The $R_{f}, \alpha$, and $Q$ values used in Table 2 were obtained by analysing the EIS data using ZView software.

It is also worth mentioning here that Hsu-Mansfeld and Hirschhorn et al. presumed the semi-circle depression model while deriving the mathematical expression for $\mathrm{CPE}$ without considering the role of film resistance, $R_{f}$ in Eq. (3) [67, 69]. Obviously, the term " $Q(j \omega)^{\alpha}$ " in Eq. (3) cannot completely determine the resultant impedance of $R_{\mathrm{el}}\left(Q R_{f}\right)$ circuit, and CPE behaviour in itself cannot be fully understood by neglecting $R_{f}$. Therefore, to understand the uniform film growth as a function of $V$, the impedance spectra are also simulated in parallel by assuming different scenarios as illustrated in Fig. 9.

Case 1 in Fig. 9a illustrates the situation where only $\alpha$ changes uniformly from 1.0 to 0.5 as commonly observed in the semi-circle depression model. Changing $\alpha$ without affecting $Q$ and $R_{f}$ does not replicate the typical impedance spectra as generated in uniform film growth (see Fig. 8) and even suppresses the CPE behaviour when $\alpha$ approaches 1.0 as demonstrated in the phase shift vs. frequency plot. Case 2 describes the resistive film scenario in which the film resistance, $R_{f}$ and the ratio $R_{f} / R_{\mathrm{el}}$ vary considerably, and CPE parameters $Q$ and $\alpha$ contribution are largely suppressed due to the dominating effect of $R_{f}$ (Fig. 9b). Under such conditions, the $\mathrm{CPE}$ behaviour starts extending towards the lower frequency part of impedance spectra. Finally, case 3 represents the most realistic situation of thin-film growth by anodizing where all $\alpha, R_{f}$, and $Q$ vary in a cooperative manner during film growth (Fig. 9c). The widening of the CPE towards low or high -frequency end of Bode plot will largely depend on the dominant effect from $Q$ and $R_{f}$. The CPE broadening for the highly capacitive film, must occur towards the higher frequency side, while for a resistive film having negligible contribution of $\mathrm{Q}$, it should be extended towards low frequency. Lastly, uniform film growth can be easily understood from the shape of the Bode plot where $R_{f}$, $Q$, and $\alpha$ are changing as a function of $V$ in the present study.

The summary of EIS analysis is provided in Fig. 10 and Table 2 in the form of inverse capacitance, $C^{-1}, k_{\text {ave }}$, and relative permittivity, $\varepsilon_{r}$ as a function of $V$. The $C^{-1}$ increases linearly with $V$ (Fig. 10a), as expected from the following equation:

$C^{-1}=\frac{d}{\varepsilon_{r} \varepsilon_{o} A}=\frac{k_{a v e} V}{\varepsilon_{r} \varepsilon_{o} A}$

in which, $\varepsilon_{o}$ is the permittivity of vacuum and $A$ is the surface area.

\section{Comparison of oxide formation factors}

Table 2 indicates that EIS analysis yields $k_{\text {ave }}$ values ranging from 1.34 to 1.62 , while the $k_{\text {ave }}$ values vary from 1.52 to 1.76 when calculated from Faraday's law. Comparison of $k$-factor obtained from different equations reveals that Hsu-Mansfeld equation $\left(C_{\mathrm{ox}, M}\right)$, Faraday's law, and normal
Table 2 Comparison of oxide formation factor, $k_{\text {ave }}$ calculated from four different approaches

\begin{tabular}{|c|c|c|c|c|}
\hline \multirow[t]{2}{*}{ at. $\% \mathrm{Gd}$} & \multicolumn{4}{|c|}{ Oxide formation factor, $k_{\mathrm{ave}} / \mathrm{nm} \mathrm{V}^{-1}$} \\
\hline & $\begin{array}{l}\text { Hsu-Mansfeld } \\
C_{\mathrm{ox}, M}=Q\left(\omega_{\max }\right)^{\alpha-1}\end{array}$ & $\begin{array}{l}\text { Bryan Hirschorn } \\
C_{\mathrm{ox}, n}=Q^{\frac{1}{\alpha}}\left(\boldsymbol{R}_{\boldsymbol{f}}\right)^{(1-\alpha) / \alpha}\end{array}$ & $\begin{array}{l}\text { Bryan Hirschorn } \\
C_{\mathrm{ox}, s}=Q^{\frac{1}{\alpha}}\left(R_{\mathrm{el}}\right)^{(1-\alpha) / \alpha}\end{array}$ & $\begin{array}{l}\text { Fara- } \\
\text { day's Law } \\
\left(d=\frac{M Q}{A z F \rho}\right)\end{array}$ \\
\hline 1.5 & 1.49 & 1.46 & 2.18 & 1.52 \\
\hline 2.0 & 1.50 & 1.49 & 2.37 & 1.66 \\
\hline 2.5 & 1.45 & 1.42 & 2.44 & 1.64 \\
\hline 3.0 & 1.46 & 1.42 & 2.57 & 1.63 \\
\hline 3.5 & 1.42 & 1.39 & 2.83 & 1.63 \\
\hline 4.5 & 1.49 & 1.42 & 3.40 & 1.70 \\
\hline 5.0 & 1.58 & 1.53 & 3.92 & 1.73 \\
\hline 5.5 & 1.61 & 1.58 & 4.46 & 1.76 \\
\hline 6.0 & 1.58 & 1.60 & 4.90 & 1.70 \\
\hline 7.0 & 1.62 & 1.58 & 5.72 & 1.71 \\
\hline 8.5 & 1.58 & 1.42 & 6.48 & 1.72 \\
\hline 9.0 & 1.53 & 1.48 & 7.63 & 1.73 \\
\hline 9.5 & 1.50 & 1.50 & 8.14 & 1.74 \\
\hline 10.0 & 1.34 & 1.31 & 7.64 & 1.75 \\
\hline
\end{tabular}



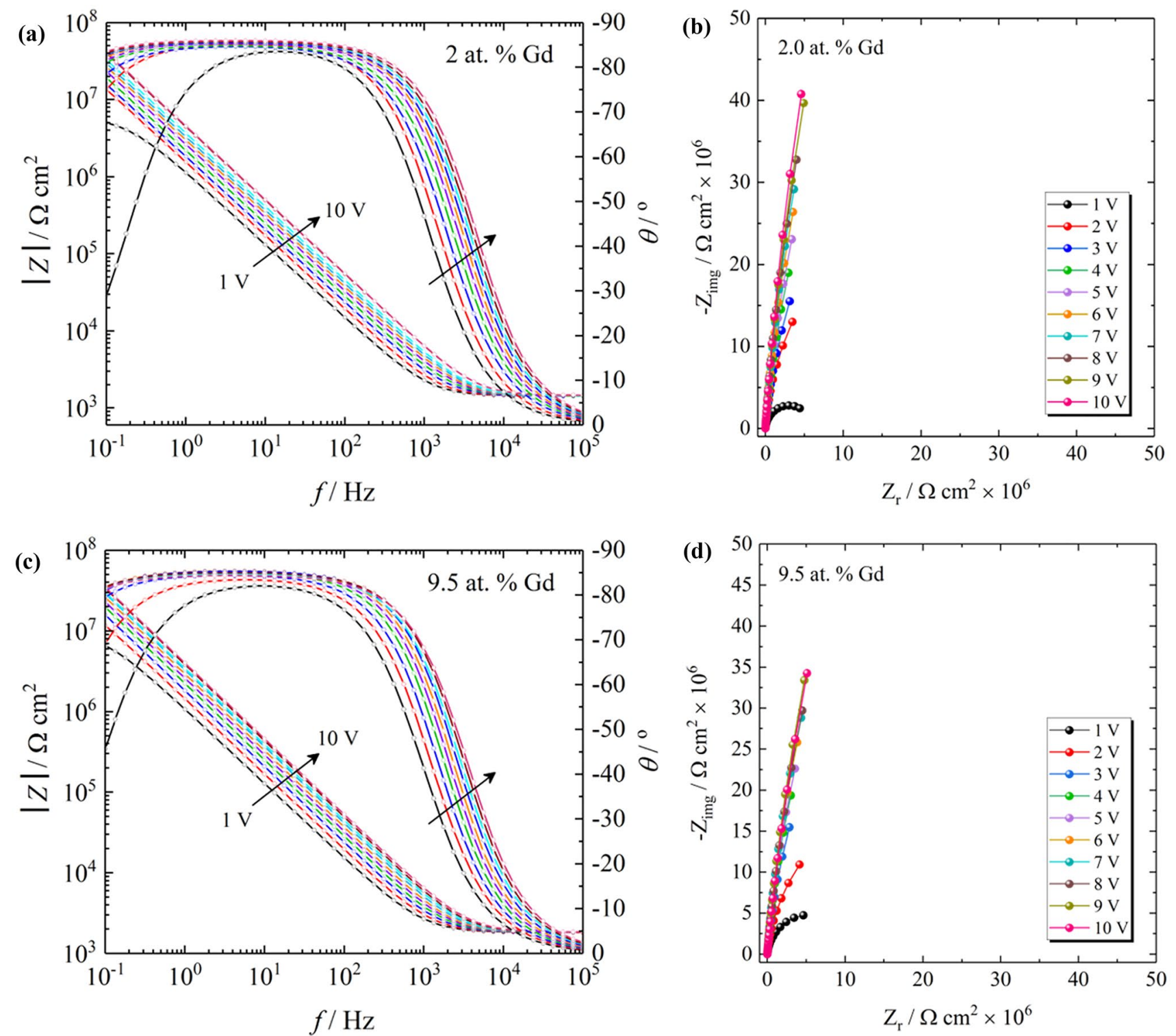

Fig. 8 Bode and Nyquist plots recorded during simultaneous CV and EIS measurements along the Al-Gd alloy library during film growth for a, b Al-2.0 at. \% Gd alloy, c, d Al-9.5 at.\% Gd alloy. The data were recorded after each $1 \mathrm{~V}$ incremental in CV to a maximum of $10 \mathrm{~V}$

distribution approach $\left(C_{\mathrm{ox}, n}\right)$ yield similar values of true capacitance. Additionally, the surface distribution $\left(C_{\mathrm{ox}, s}\right)$ akin to Brug's formula [68] gives an unrealistically high estimation of $k_{\text {ave }}$ values. As the contribution of $R_{f}$ is negligible in the surface distribution approach, it is probable that the approach will give an erroneous prediction of $k_{\text {ave }}$ value when applied to the passive oxide film. Slightly higher $k_{\text {ave }}$ values are obtained from the Faraday's law as the $k_{\text {ave }}$ from EIS measurement involves the calculation of film thickness directly resulting from the film, while Faraday's law requires the anodizing charge (including side reactions) to be used directly for the determination of $d$ values. The additional charge consumed in side reactions such as oxygen gas evolution and metal dissolution affects the $k_{\text {ave }}$. Moreover, the mixed matter approach was assumed for the densities and molecular masses of the locally grown oxide film. As the few $\mathrm{nm}$ thin films are difficult to characterize, the errors in $k_{\text {ave }}$ values from EIS and Faraday's methods are inevitable. Precise assumptions of material constants, accurate $C_{\mathrm{ox}}$ estimation, and negligible side reactions would ensure comparable $k_{\text {ave }}$ values from EIS and Faraday's law. 
Fig. 9 Simulated Nyquist and Bode plots: a $\alpha$ varies, $\mathbf{b} \alpha$ and $R_{f}$ varies, $\mathrm{c} \alpha, R_{f}, Q$ changes. The electrolyte resistance $R_{\mathrm{el}}$ is kept constant for these simulations
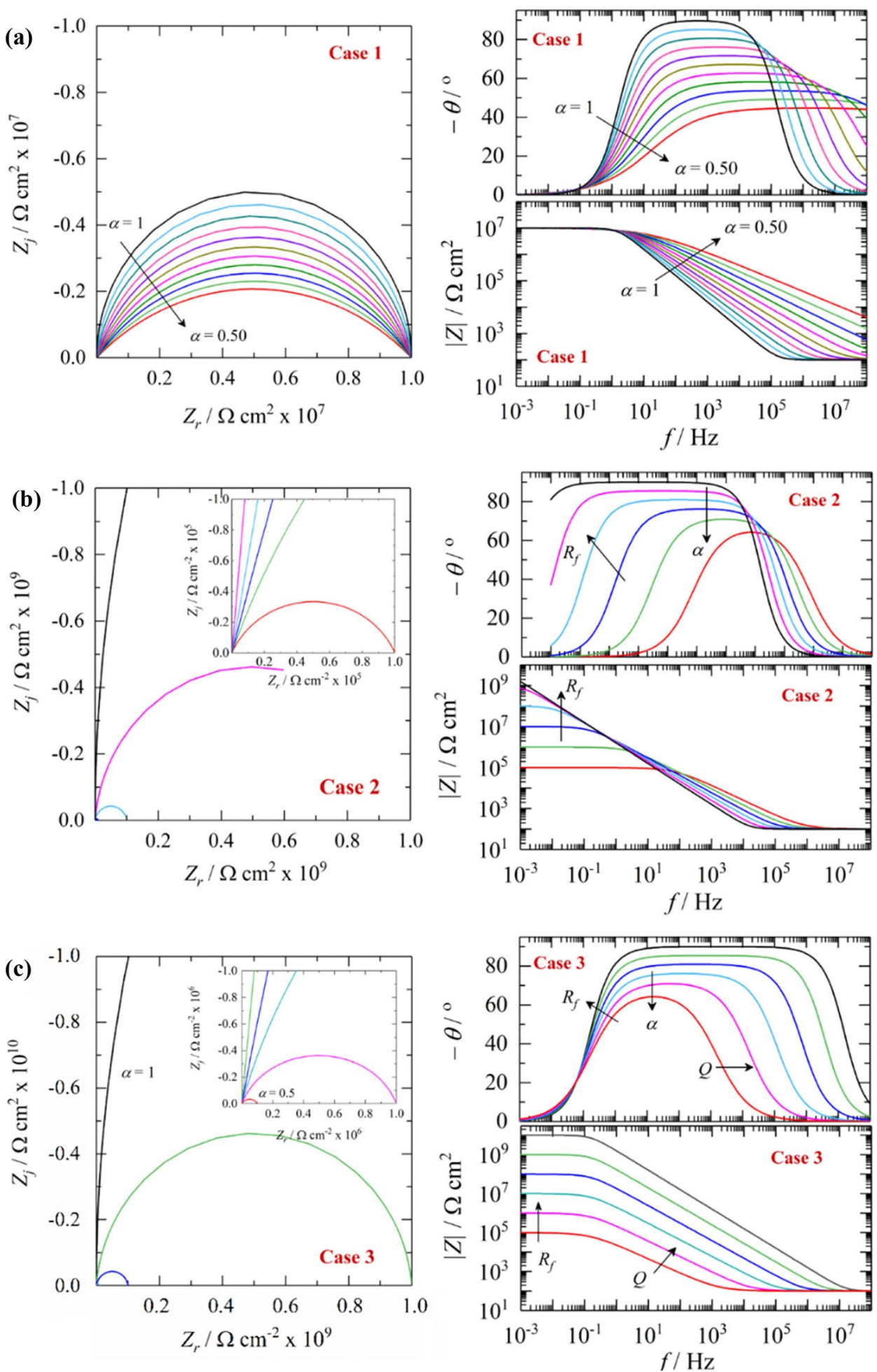

\section{Dielectric constant}

The $\varepsilon_{r}$ (Fig. 10b) was determined from the slope of $V$ plotted against $C^{-1}$. Figure $10 \mathrm{~b}$ shows that $\varepsilon_{r}$ values are ranging from 13.5 to 23.0 for $\mathrm{Al}-\mathrm{Gd}$ alloys indicating that addition of $\mathrm{Gd}$ to $\mathrm{Al}$ improves the dielectric constant of pure alumina.
Because of material's constant assumption in mixed matter theory, a 10\% error bar is also included in Fig. 10b. $\varepsilon_{r}$ of anodic films containing mixed oxides lies between the values reported for pure $\mathrm{Al}_{2} \mathrm{O}_{3}\left(\varepsilon_{r}\right.$ for $\left.\mathrm{Al}_{2} \mathrm{O}_{3}=9-13\right)$ and pure $\mathrm{Gd}_{2} \mathrm{O}_{3}\left(\varepsilon_{r}\right.$ for $\mathrm{Gd}_{2} \mathrm{O}_{3}=10-24$ on single and polycrystalline thin-films) [24, 27]. $\varepsilon_{r}$ values of both $\mathrm{Al}_{2} \mathrm{O}_{3}$ and $\mathrm{Gd}_{2} \mathrm{O}_{3}$ 
Fig. 10 a Inverse capacitance, $C^{-1}$ as a function of $V \mathbf{b}$ relative permittivity, $\varepsilon_{r}$ from Faraday's law. The EIS data is estimated using ZView software
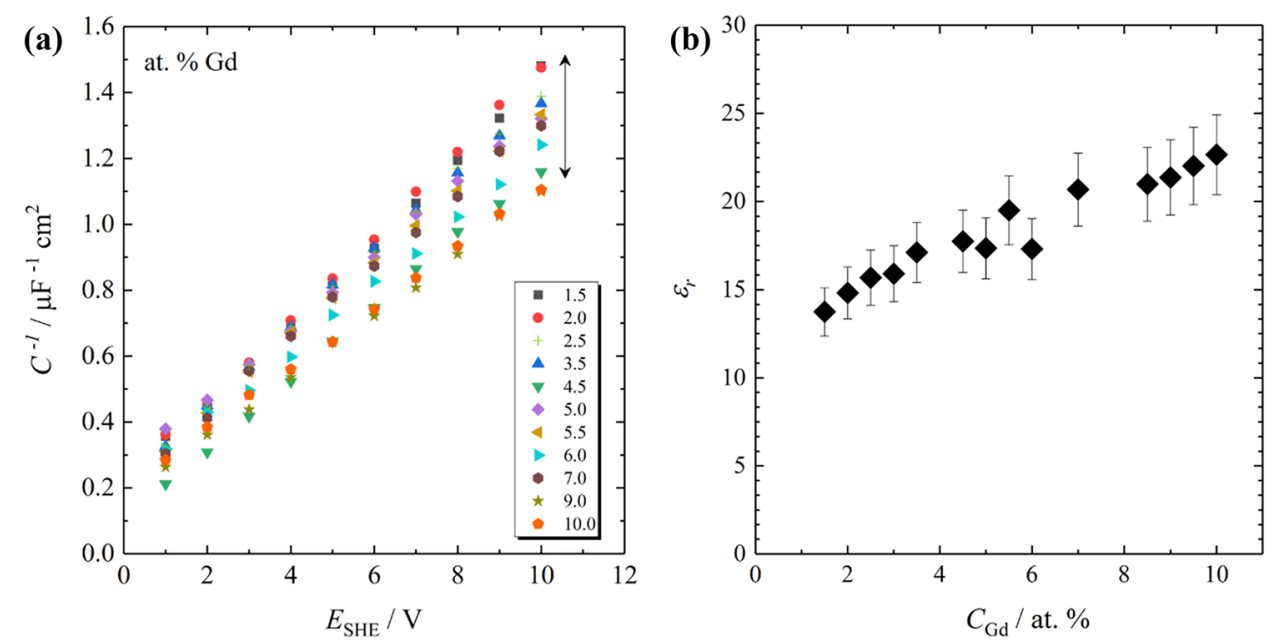

in phosphate buffer ( $\mathrm{pH}$ 8.20) using SDCM approach were found out to be 12.7 and 20.5 respectively. This result is a prominent example of the advantage of combinatorial investigations over common batch specimen production, where the property of interest ( $\varepsilon_{r}$ in the present case) can be readily identified for wide range of compositions with high accuracy, since the history of preparation, surface treatment, air contact, and other steps are identical. The variation of the screened property can be solely attributed to the difference in composition.

The efficiency of film formation, composition, and nature of amorphous and crystalline phases within the mixed structure can be estimated by a combination of FIB-TEM, XPS, RBS analyses which in the present case is not possible owing to the ultra-thin anodic films. At such a low value $(\sim 1-15 \mathrm{~nm})$, obtaining a smooth RBS spectrum and its further simulation is a very challenging task. No visible sign of gas evolution, extremely low dissolution of rare-earth elements in phosphate buffer solution, and detection of negligible Ho (14 ppb) using the SDCM-ICPSOES approach indicates the negligible consumption of ionic current in various side reactions $[59,64]$.

\section{Conclusions}

In summary, a combination of a high-throughput simulation and high-throughput scanning was investigated in a chosen electrolyte on an Al-Gd compositional spread covering a range from 1.0 to 10 . at. $\% \mathrm{Gd}$. The results of the present study must be interpreted in terms of used electrolyte and special SDCM geometry. The main conclusions are as follows:

1. Novel E-pH and phase diagrams were simulated by coupling conventional and first-principles approaches, and it directly allowed us to predict the domains of thermodynamic predominance for rapid identification of electrolytes on Al-Gd alloys in a given aqueous system.

2. XRD patterns did not show additional phase formation in mixed alloy chemistries except the reduction of $\mathrm{Al}(111)$ peak intensity, revealing the loss of crystallinity in the chosen composition range.

3. From the SEM images of the as-deposited film, three distinct regions were identified: large grains typical of fcc phase in Al-rich region, disappearance of these grains in the middle of the compositional spread, and evolution of upright needle like morphology in alloys of high Gd concentrations.

4. Composition-dependent changes in the film formation factor and relative permittivity, and inverse capacitance were estimated indicating the influence of Gd addition while maintaining the passivation behaviour of alumina. These changes were linear and could be directly correlated to the nanoscopic change of the morphology as a function of alloy composition.

Supplementary information The online version contains supplementary material available at https://doi.org/10.1007/s10008-021-05012-x.

Funding Open access funding provided by Johannes Kepler University Linz. The financial support by the Austrian Federal Ministry of Science, Research and Economy and the National Foundation for Research, Technology and Development through funding of the Christian Doppler Laboratory for Combinatorial Oxide Chemistry (COMBOX) is gratefully acknowledged.

Open Access This article is licensed under a Creative Commons Attribution 4.0 International License, which permits use, sharing, adaptation, distribution and reproduction in any medium or format, as long as you give appropriate credit to the original author(s) and the source, provide a link to the Creative Commons licence, and indicate if changes were made. The images or other third party material in this article are included in the article's Creative Commons licence, unless indicated 
otherwise in a credit line to the material. If material is not included in the article's Creative Commons licence and your intended use is not permitted by statutory regulation or exceeds the permitted use, you will need to obtain permission directly from the copyright holder. To view a copy of this licence, visit http://creativecommons.org/licenses/by/4.0/.

\section{References}

1. Maier WF, Stöwe K, Sieg S (2007) Combinatorial and highthroughput materials science. Angew Chem Int Ed Engl 46:6016-6067

2. Hao H, Huang J, Liu P, Xue Y, Wang J, Ren K, Jin Q, Ji J, Greiner A, Agarwal S (2021) Rapid build-up of high-throughput screening microarrays with biochemistry gradients via light-induced thiolene "click" chemistry. J Mater Chem B 9:3032-3037

3. Miracle D, Majumdar B, Wertz K, Gorsse S (2017) New strategies and tests to accelerate discovery and development of multiprincipal element structural alloys. Scr Mater 127:195-200

4. Singh A, Talekar M, Tran TH, Samanta A, Sundaram R, Amiji M (2014) Combinatorial approach in the design of multifunctional polymeric nano-delivery systems for cancer therapy. J Mater Chem B 2:8069-8084

5. Coury FG, Clarke KD, Kiminami CS, Kaufman MJ, Clarke AJ (2018) High throughput discovery and design of strong multicomponent metallic solid solutions. Sci Rep 8:8600

6. Klemm SO, Schauer J-C, Schuhmacher B, Hassel AW (2011) A microelectrochemical scanning flow cell with downstream analytics. Electrochim Acta 56:4315-4321

7. Akbarzadeh AR, Ozoliņš V, Wolverton C (2007) First-principles determination of multicomponent hydride phase diagrams: application to the Li-Mg-N-H system. Adv Mater 19:3233-3239

8. Jain A, Hautier G, Ong SP, Moore CJ, Fischer CC, Persson KA, Ceder G (2011) Formation enthalpies by mixing GGA and GGA + U calculations. Phys Rev B 84:045115

9. Kirklin S, Meredig B, Wolverton C (2013) High-throughput computational screening of new Li-Ion battery anode materials. Adv Energy Mater 3:252-262

10. Hattrick-Simpers JR, Tan Z, Oguchi H, Chiu C, Heilweil EJ, Maslar JE, Bendersky LA (2011) A combinatorial characterization scheme for high-throughput investigations of hydrogen storage materials. Sci Technol Adv Mater 12:054207

11. Hafiz H, Khair AI, Choi H, Mueen A, Bansil A, Eidenbenz S, Wills J, Zhu JX, Balatsky AV, Ahmed T (2018) A high-throughput data analysis and materials discovery tool for strongly correlated materials. npj Comput Mater 4:63

12. Sanvito S, Oses C, Xue J, Tiwari A, Zic M, Archer T, Tozman P, Venkatesan M, Coey M, Curtarolo S (2017) Accelerated discovery of new magnets in the Heusler alloy family. Sci Adv 3:e1602241

13. Mardare AI, Ludwig A, Savan A, Hassel AW (2014) Electrochemistry on binary valve metal combinatorial libraries: niobiumtantalum thin films. Electrochim Acta 140:366-375

14. Iwasaki Y, Ishida M, Shirane M (2020) Predicting material properties by integrating high-throughput experiments, high-throughput ab-initio calculations, and machine learning. Sci Technol Adv Mater 21:25-28

15. Hautier G, Jain A, Ong PS (2012) From the computer to the laboratory: materials discovery and design using first-principles calculations. J Mater Sci 47:7317-7340

16. Mao Z, Seidman DN, Wolverton C (2011) First-principles phase stability, magnetic properties and solubility in aluminum - rareearth (Al - RE) alloys and compounds. Acta Mater 59:3659-3666
17. Petit L, Svane A, Szotek Z, Temmerman WM (2005) First-principles study of rare-earth oxides. Phys Rev B: Condens Matter Mater Phys 72:205118

18. Potyrailo R, Rajan K, Stoewe K, Chisholm B, Dakota N, States U, Lam H (2011) Combinatorial and high-throughput screening of materials libraries : review of state of the art. ACS Comb Sci 13:579-633

19. Mardare AI, Yadav AP, Wieck AD, Stratmann M, Hassel AW (2008) Combinatorial electrochemistry on Al-Fe alloys. Sci Technol Adv Mater 9:035009

20. Blazey KW, Rohrer H (1968) Antiferromagnetism and the magnetic phase diagram of $\mathrm{GdAlO}_{3}$. Phys Rev 173:574-580

21. Cashion JD, Cooke AH, Thorp TL, Wells MR (1970) Magnetic properties of gadolinium ortho-aluminate. Proc R Soc A 318:473-495

22. Petrov D (2011) Nanocrystalline $\mathrm{GdAlO}_{3}$ : XPS, EPR and magnetic susceptibility studies. Appl Phys A: Solids Surf 104:1237-1242

23. Kukli K, Hatanpää T, Ritala M, Leskelä M (2007) Atomic layer deposition of gadolinium oxide films. Chem Vap Deposition 13:546-552

24. Cheng X, Xu D, Song Z, He D, Yu Y, Zhao Q, Shen D (2009) Characterization of gadolinium oxide film by pulse laser deposition. Appl Surf Sci 256:921-923

25. Dakhel AA (2005) Optical and dielectric properties of gadolinium-erbium oxide films prepared on $\mathrm{Si}(100)$ substrate. Appl Phys A: Solids Surf 80:1033-1037

26. Sahoo NK, Senthilkumar M, Thakur S, Bhattacharyya D (2002) Correlation of optical and microstructural properties of $\mathrm{Gd}_{2} \mathrm{O}_{3}$ thin films through phase-modulated ellipsometry and multi-mode atomic force microscopy. Appl Surf Sci 200:219-230

27. Hong M, Kwo J, Kortan AR, Mannaerts JP, Sergent AM (1999) Epitaxial cubic gadolinium oxide as a dielectric for gallium arsenide passivation. Science 283:1897-1900

28. Zhou J-P, Chai C-L, Yang S-Y, Liu Z-K, Song S-L, Li Y-L, Chen $\mathrm{N}-\mathrm{F}$ (2004) Properties of high $\mathrm{k}$ gate dielectric gadolinium oxide deposited on $\mathrm{Si}\left(\begin{array}{lll}1 & 0 & 0\end{array}\right)$ by dual ion beam deposition (DIBD). J Cryst Growth 270:21-29

29. Watanabe K, Sakairi M, Takahashi H, Takahiro K, Nagata S, Hirai S (2001) Formation of composite oxide films on aluminum by sol-gel coating and anodizing - for the development of high-performance aluminum electrolytic capacitors. Electrochemistry 69:407-413

30. Habazaki H, Koyama S, Aoki Y, Sakaguchi N, Nagata S (2011) Enhanced capacitance of composite anodic $\mathrm{ZrO}_{2}$ films comprising high permittivity oxide nanocrystals and highly resistive amorphous oxide matrix. ACS Appl Mater Interfaces 3:2665-2670

31. Woldemedhin MT, Raabe D, Hassel AW (2011) Grain boundary electrochemistry of B-Type $\mathrm{Nb}-\mathrm{Ti}$ alloy using a scanning droplet cell. Phys Status Solidi Appl Mater Sci (a) 208:1246-1251

32. Hassel AW, Lohrengel MM (1997) The scanning droplet cell and its application to structured nanometer oxide films on aluminium. Electrochim Acta 42:3327-3333

33. Small L, Cook A, Apblett C, Ihlefeld JF, Brennecka G, Duquette D (2012) An automated electrochemical probe for evaluation of thin films. J Electrochem Soc 159:F87-F90

34. Casillas N, Charlebois SJ, Smyrl WH, White HS (1993) Scanning electrochemical microscopy of precursor sites for pitting corrosion on titanium. J Electrochem Soc 140:L142-L145

35. Woldemedhin MT, Raabe D, Hassel AW (2012) Characterization of thin anodic oxides of Ti-Nb alloys by electrochemical impedance spectroscopy. Electrochim Acta 82:324-332

36. Kollender JP, Mardare AI, Hassel AW (2013) Photoelectrochemical scanning droplet cell microscopy (PE-SDCM). ChemPhysChem 14:560-567

37. Hafner M, Mardare AI, Hassel AW (2013) Vapour phase co-deposition of Al-Cu thin film alloys. Phys Status Solidi A 210:1006-1012 
38. Hassel AW, Fushimi K, Seo M (1999) An agar-based silverlsilver chloride reference electrode for use in micro-electrochemistry. Electrochem Commun 1:180-183

39. Klemm SO, Schauer J-C, Schuhmacher B, Hassel AW (2011) High throughput electrochemical screening and dissolution monitoring of $\mathrm{Mg}-\mathrm{Zn}$ material libraries. Electrochim Acta 56:9627-9636

40. Pourbaix M (1974) Atlas of electrochemical equilibria in aqueous solutions. National Association of Corrosion Engineers, Houston, USA

41. Bard AJ, Parsons R, Jordan J (1985) Standard potentials in aqueous solution. Taylor \& Francis, London, UK

42. Geochemist's Workbench (2019). https://www.gwb.com. Accessed 19 Jul 2019

43. FactSage (2019). http://www.factsage.com. Accessed 05 May 2019

44. Medusa (2019). https://www.kth.se/che/medusa. Accessed 18 Nov 2019

45. Materials Project (2020). https://materialsproject.org. Accessed 23 Apr 2020

46. Jain A, Hautier G, Moore CJ, Ong SP, Fischer CC, Mueller T, Persson KA, Ceder G (2011) A high-throughput infrastructure for density functional theory calculations. Comput Mater Sci 50:2295-2310

47. Persson KA, Waldwick B, Lazic P, Ceder G (2012) Prediction of solid-aqueous equilibria: scheme to combine first-principles calculations of solids with experimental aqueous states. Phys Rev B: Condens Matter Mater Phys 85:235438

48. Car R, Parrinello M (1985) Unified approach for molecular dynamics and density-functional theory. Phys Rev Lett 55:2471-2474

49. Gschneidner KA, Calderwood FW (1988) The Al-RE (aluminumrare earth) systems. Bull Alloy Phase Diagr 9:658-668

50. Mardare AI, Grill CD, Pötzelberger I, Etzelstorfer T, Stangl J, Hassel AW (2016) Anodic oxide formation on aluminium-terbium alloys. J Solid State Electrochem 20:1673-1681

51. Revie RW (2000) Uhlig's corrosion handbook. John Wiley \& Sons, Inc., New York, USA

52. Schweitzer GK, Pesterfield LL (2010) The aqueous chemistry of the elements. Oxford University Press, Oxford, UK

53. Crossland AC, Thompson GE, Skeldon P, Wood GC, Smith CJE, Habazaki H, Shimizu K (1998) Anodic oxidation of Al-Ce alloys and inhibitive behaviour of cerium species. Corros Sci 40:871-885

54. Herrera-Erazo AE, Habazaki H, Shimizu K, Skeldon P, Thompson GE (2000) Anodic film growth on Al-Nd alloys. Corros Sci 42:1823-1830

55. Habazaki H, Skeldon P, Thompson GE, Wood GC, Shimizu K (1997) Anodic film formation on a sputter-deposited amorphous Al-40 At. \% Sm alloy. J Mater Res 12:1885-1891

56. Torrescano-Alvarez JM, Curioni M, Habazaki H, Hashimoto T, Skeldon P, Zhou X (2019) Incorporation of alloying elements into porous anodic films on aluminium alloys: the role of cell diameter. Electrochim Acta 296:783-789

57. Thompson GE, Habazaki H, Shimizu K, Sakairi M, Skeldon P, Zhou X, Wood GC (1999) Anodizing of aluminium alloys. Aircr Eng Aerosp Technol 71:228-238
58. Randall JJ, Bernard WJ (1975) A radiotracer study of the anodization of aluminum in aqueous phosphate solutions. Electrochim Acta 20:653-661

59. Takahashi H, Fujimoto K, Nagayama M (1988) Effect of pH on the distribution of anions in anodic oxide films formed on aluminum in phosphate solutions. J Electrochem Soc 135:1349-1353

60. Firsching FH, Brune SN (1991) Solubility products of the trivalent rare-earth phosphates. J Chem Eng Data 36:93-95

61. Liu X, Byrne RH (1997) Rare earth and yttrium phosphate solubilities in aqueous solution. Geochim Cosmochim Acta 61:1625-1633

62. Byrne RH, Kim K-H (1993) Rare earth precipitation and coprecipitation behavior: the limiting role of $\mathrm{PO}_{4}{ }^{3-}$ on dissolved rare earth concentrations in seawater. Geochim Cosmochim Acta 57:519-526

63. Cetiner ZS, Wood SA, Gammons CH (2005) The aqueous geochemistry of the rare earth elements. Part XIV. The solubility of rare earth element phosphates from 23 to $150{ }^{\circ} \mathrm{C}$. Chem Geol 217:147-169

64. Shahzad K, Mardare CC, Recktenwald D, Mardare AI, Hassel AW (2019) Formation of nano-scale composite anodic films on aluminium-holmium alloys. Electrochim Acta 297:888-904

65. Zhou F, LeClere DJ, Garcia-Vergara SJ, Hashimoto T, Molchan IS, Habazaki H, Skeldon P, Thompson GE (2010) Incorporation and migration of phosphorus species in anodic alumina films containing tungsten tracer layers. J Electrochem Soc 157:C437

66. Orazem ME, Frateur I, Tribollet B, Vivier V, Marcelin S, Pebere N, Bunge AL, White EA, Riemer DP, Musiani M (2013) Dielectric properties of materials showing constant-phase-element (CPE) impedance response. J Electrochem Soc 160:C215-C225

67. Hsu CH, Mansfeld F (2001) Technical note: concerning the conversion of the constant phase element parameter Y0 into a capacitance. Corrosion 57:747-748

68. Brug GJ, van den Eeden ALG, Sluyters-Rehbach M, Sluyters JH (1984) The analysis of electrode impedances complicated by the presence of a constant phase element. J Electroanal Chem Interfacial Electrochem 176:275-295

69. Hirschorn B, Orazem ME, Tribollet B, Vivier V, Frateur I, Musiani M (2010) Determination of effective capacitance and film thickness from constant-phase-element parameters. Electrochim Acta 55:6218-6227

70. Hirschorn B (2010) Distributed time-constant impedance responses interpreted in terms of physically meaningful properties. Doctoral dissertation, University of Florida, Gainesville

71. Hirschorn B, Orazem ME, Tribollet B, Vivier V, Frateur I, Musiani M (2010) Constant-phase-element behavior caused by resistivity distributions in films I. Theory. J Electrochem Soc 157:C452-C457

Publisher's Note Springer Nature remains neutral with regard to jurisdictional claims in published maps and institutional affiliations. 